\title{
TRANSFORMAÇÕES NA ESTRUTURA OCUPACIONAL DO NORTE DO BRASIL COM FOCO NA DENDEICULTURA
}

\author{
Dalva Maria da Mota ${ }^{1}$ \\ Otavio Valentim Balsadi ${ }^{2}$ \\ Moisés Mourão Júnior ${ }^{3}$
}

\begin{abstract}
RESUMO
O objetivo do artigo é analisar transformações que têm ocorrido na estrutura ocupacional rural do Norte, por meio de dados estatísticos e de estudos de caso na produção de dendê, no Pará. Pretendese, também, construir um quadro de análise antes da implementação da reforma trabalhista amparada na Lei n. 13.467/2017. As principais conclusões mostram que o Pará detém a maior parte da População Economicamente Ativa (PEA) ocupada de 10 anos ou mais de idade, no período 2004 a 2014, mas com queda contínua; situação também observada nos maiores produtores de commodities no Norte (Tocantins, Rondônia e Pará). Tanto os dados secundários quanto primários mostram a predominância de homens no assalariamento e no trabalho familiar, a redução da participação das mulheres na agricultura e o envelhecimento da força de trabalho. Há indícios de substituição de vínculos duradouros e formalizados no assalariamento por vínculos curtos e ocasionais.
\end{abstract}

Palavras-chave: Trabalho Agrícola, Nordeste Paraense, Produção de dendê, Ocupações rurais.

\section{TRANSFORMATIONS IN THE OCCUPATIONAL STRUCTURE OF NORTH BRAZIL FOCUSING ON DENDEICULTURE}

\begin{abstract}
The aim of this paper is to analyze transformations that have occurred in the rural occupational structure of the North region in Brazil through statistical data and case studies on oil palm production in Pará. It also intends to build a framework of analysis before the implementation of labor reform supported by Law no 13,467/2017. The main outcomes show that Pará holds most of the employed agricultural EAP of 10 years of age and over, from 2004 to 2014, but in continuous decline. This situation is also observed in the largest States producers of commodities in the North (Tocantins, Rondônia and Pará). Both secondary and primary data show the predominance of men in wage and family labor, the reduced participation of women in agriculture and the aging workforce. There is evidence of replacement of formalized bonds in the wage labor market by short and occasional bonds.
\end{abstract}

Keywords: Agricultural work, Northeast Paraense, Oil palm production, Rural Occupations.

\section{INTRODUÇÃO}

Estudos recentes analisam que a crise ambiental internacional em conjunto com outros fatores como o "estreitamento dos vínculos entre o capital financeiro especulativo e o empresariado rural" (Cunha, 2017, p.302), impulsionam uma corrida por terras num contexto de desnacionalização do Estado e de transnacionalização do capital (Lima; Oliveira, 2019). Autores reconhecem que sob argumentos ambientais, tal processo tem se viabilizado por meio do controle de recursos naturais,

\footnotetext{
${ }^{1}$ Doutora em Sociologia, pesquisadora da Embrapa Amazônia Oriental, Belém (PA), bolsista de produtividade do Conselho Nacional de Desenvolvimento Científico e Tecnológico (CNPq). Telefone: (091) 3204-1001. E-mail: dalva.mota@embrapa.br

${ }^{2}$ Doutor em Economia, pesquisador da Embrapa, Secretaria de Inteligência e Relações Estratégicas. Brasília. Telefone: (061) 3448-1818. E-mail: otavio.balsadi@embrapa.br

${ }^{3}$ Doutor em Geografia, pesquisador da Embrapa Amazônia Oriental, Belém. E-mail: moisesmourao@embrapa.br
} 
seja com propósito de especulação, seja para a produção de algumas commodities requeridas pelo mercado mundial (Backhouse, 2013; Bonnano, 2018; Cunha, 2017). A partir deste modelo, constatam-se transformações na legislação relativa à regulamentação do trabalho com a redução dos direitos dos trabalhadores e, consequentemente, mudanças na estrutura ocupacional.

Neste contexto, a Amazônia tem sido mais intensamente incorporada aos processos de transnacionalização do capital por meio de grandes projetos de infraestrutura financiados pelo Estado nas últimas décadas. Segundo Castro (2017)

Desde os anos 1990 observa-se um movimento de expansão das fronteiras do agronegócio na Amazônia. Os espaços transfronteiriços constituem-se em novas áreas de expansão de mercado, que tendem a se tornar mais acessíveis em função da nova logística de transportes nas áreas de fronteira, contando também com a participação de empresas de diversos setores econômicos (Castro, 2017, p. 9).

Mais especificamente, Little (2013, p. 13) afirma:

Na Amazônia, a busca frenética mundial por commodities e fontes de energia está gerando uma rápida expansão no uso de terras agrícolas para a produção de grãos e biocombustíveis, na construção de grandes barragens hidrelétricas e nas atividades de mineração espalhados por toda a bacia Amazônica, transformando a região em uma nova fronteira global.

Corresponde ao perfil de 'rápida expansão' a produção de dendê na Amazônia Oriental ${ }^{4}$ nas últimas décadas. Por um lado, é alternativa energética para combater as mudanças climáticas, as consequências da emissão de gases de efeito estufa e a instabilidade dos preços do petróleo. Por outro, tem preço competitivo (elevada produtividade -7t/ha e ocupa menos terra quando comparado à soja); versatilidade (óleo vegetal mais usado para a cocção de alimentos mundialmente, cosméticos, indústria química, farmacêuticos, etc.); e oportuniza a diminuição do uso de combustíveis fósseis pela agregação ao biodiesel. Entretanto, tal expansão implica controvérsias associadas à concentração de terras, problemática ambiental e conflitos sócio territoriais e trabalhistas, com consequências na estrutura ocupacional, na organização política dos trabalhadores e, mais recentemente, em iniciativas restritivas ao uso dos derivados de dendê em alimentos pela expressão 'livre de óleo de palma' impressa nas embalagens de alguns produtos em supermercados na Europa ${ }^{5}$.

\footnotetext{
${ }^{4}$ No estado do Pará, cultiva-se dendê há décadas, mas só recentemente a expansão se dá com subsídios públicos oriundos do Programa Nacional de Produção e Uso de Biodiesel (PNPB) lançado em 2004, do Programa de Produção Sustentável de Óleo de Palma (PPSOP), e com o ZAE-PALMA em 2010 (indicação de 29 milhões de áreas desmatadas em 10 estados da Amazônia legal), crédito e integração de agricultores familiares, isenções fiscais e condições mais favoráveis nos leilões de biodiesel por meio do selo combustível social: $40 \%$ no Sul, $30 \%$ no Sudeste e nas demais regiões seriam $15 \%$. Três linhas de financiamento deram suporte à expansão do dendê: PRONAF-ECO, PRODUSA E PROPFLORA. Apesar da previsão da produção de biodiesel, sob o argumento de um combustível limpo para minimizar o uso de combustíveis fósseis, a produção de dendê no Pará é predominantemente direcionada à agroindústria de alimentos, considerando que o Brasil importa cerca de $80 \%$ do total para atender a sua demanda do óleo vegetal mais consumido no mundo.

${ }^{5} \mathrm{https}$ //www.ethicalconsumer.org/palm-oil/palm-oil-free-list; https://www.independent.co.uk/life-style/palm-oilhealth-impact-environment-animals-deforestation-heart-a8505521.html;

https://www.rainforest-rescue.org/topics/palm-oil\#more
} 
Considerando o panorama, interessa neste artigo a problemática da estrutura ocupacional, uma vez que se estima a criação direta de 20 mil empregos nos monocultivos e nas usinas de processamento de dendê no Pará (Abrapalma, 2014). Houve a incorporação de cerca de 1500 agricultores familiares na produção de dendê, em áreas dos seus estabelecimentos, sob a condição de uma agricultura por contrato com as agroindústrias. Relações de assalariamento desta magnitude e contratos de produção com agricultores familiares representam novidades que coexistem com relações não mercantis em uma região que abriga modos de vida tradicionais, que possuem outra concepção de espaço-tempo, portanto, não mediada pelo mercado.

Dada a relevância e atualidade do tema, o artigo tem por objetivo analisar transformações que têm ocorrido na estrutura ocupacional da população rural do Norte do Brasil e, mais especificamente, relações de trabalho na dendeicultura. Está composto por cinco partes: i) Introdução; ii) Procedimentos metodológicos; iii) Mercado de trabalho agrícola e rural no Norte; iv) Relações de trabalho na dendeicultura paraense: estudos de caso; e v) Conclusões.

\section{PROCEDIMENTOS METODOLÓGICOS}

A pesquisa foi realizada a partir da revisão de dados secundários para apreender as transformações na região Norte e de estudos de caso, com levantamento de dados primários na região produtora de dendê no Nordeste Paraense (NEP).

Para os dados secundários, a fonte é a Pesquisa Nacional por Amostra de Domicílios (PNAD), realizada pelo Instituto Brasileiro de Geografia e Estatística (IBGE) ${ }^{6}$. Os dados referem-se ao trabalho único ou principal que as pessoas de 10 anos ou mais de idade tinham na semana de referência da pesquisa, normalmente a última ou a penúltima do mês de setembro de cada ano. Por População Economicamente Ativa (PEA) ocupada entende-se o conjunto de pessoas que possuíam trabalho durante todo ou parte do período da semana de referência ${ }^{7}$. Quanto à posição na ocupação, as categorias são as seguintes: empregador; empregado; conta própria; não remunerado; trabalhador na produção para o próprio consumo (IBGE, 2017).

A distribuição dos ocupados, por atividade, obedece à classificação das atividades econômicas feitas pelo IBGE para fins de pesquisas domiciliares (CNAE-Domiciliar) (Concla, 2018). A expansão das amostras da PNAD para a obtenção do total de ocupados no período 2004-2014 foi feita com as ponderações disponibilizadas pelo IBGE para esta década, conhecida como 'Revisão 2013' (IBGE, 2013). As taxas de crescimento anuais foram estimadas por meio do modelo de regressões log-

\footnotetext{
${ }^{6}$ A Pesquisa Nacional por Amostra de Domicílios (PNAD) foi realizada anualmente pelo Instituto Brasileiro de Geografia e Estatística (IBGE) até 2015, quando foi substituída pela PNAD Contínua. Vale dizer que a partir de 2004 a PNAD tornou-se, de fato, uma pesquisa nacional, abrangendo as áreas urbanas e rurais de todos os Estados e regiões.

${ }^{7}$ Também fazem parte da PEA ocupada as pessoas que não exerceram o trabalho remunerado que tinham no período especificado, por motivo de férias, licenças, faltas, greves, entre outros.
} 
lineares, com as informações referentes aos anos de 2004, 2005, 2006, 2007, 2008, 2009, 2011, 2012, 2013 e 2014. Em 2010, por causa do Censo Demográfico, a PNAD não foi realizada.

Para os dados primários, foram realizadas entrevistas com agricultores familiares autodesignados chefes de família e com trabalhadores assalariados. Em se tratando dos agricultores familiares, a pesquisa foi realizada em 08 municípios $^{8}$ selecionados por serem os maiores produtores de dendê no estado do Pará entre 2014 e 2016. Entrevistas semiestruturadas foram realizadas em 162 estabelecimentos agrícolas com os autodesignados chefes de família. Quanto aos assalariados, 71 trabalhadores que estavam empregados ou recém demitidos (em torno de 5\%) foram entrevistados entre 2018 e 2019. Deste total, os homens foram 80\% dos entrevistados, por predominarem no assalariamento, expressão das relações de hierarquia que organizam as assimetrias construídas socialmente entre homens e mulheres. Lideranças de sindicatos que afiliam agricultores familiares e trabalhadores assalariados também foram entrevistadas.

A intersecção de dados secundários e primários em diferentes escalas objetivou construir simultaneamente um quadro da estrutura ocupacional e seus reflexos no cotidiano do trabalho na escala local.

\section{MERCADO DE TRABALHO AGRÍCOLA E RURAL NO NORTE}

Visão panorâmica da Região Norte, no período 2004-2014, com foco no Estado do Pará

Particularidades marcam a Região Norte em se tratando da PEA, por ser uma região na qual os grupos sociais e as formas de produção são diversas e abrangem um escopo constituído tanto por relações assalariadas, quanto por aquelas que sustentam sociedades tradicionais cujas lógicas de trabalho transcendem o plano econômico, dentre outras formas (Castro, 1994).

Sob tal compreensão, objetiva-se traçar um quadro geral do mercado de trabalho agrícola e rural na região Norte, com maior destaque para o principal Estado produtor, que é o Pará, de modo a trazer subsídios de relevo que possam compor um contexto no qual se aprofundará, com base em dados primários de pesquisa de campo, as complexas realidades do mundo do trabalho na atividade da dendeicultura.

Evolução da PEA agrícola

A partir dos dados da Pnad/IBGE de 2004 a 2014, dimensiona-se a contribuição da Região Norte quanto à PEA agrícola nacional, a qual situou-se entre 10 e $12 \%$ ao longo do período avaliado (Tabela 1).

\footnotetext{
${ }^{8} \mathrm{O}$ número de estabelecimentos visitados por município foi: Acará (12), Capitão Poço (1), Concórdia do Pará (11), Irituia (16), São Domingos do Capim (36), Tailândia (36), Moju (31) e Tomé-Açu (19).
} 
Como salientam Balsadi e Del Grossi (2016, p. 85):

Em termos de participação relativa das regiões no total da PEA ocupada na agricultura, notase um quadro com poucas variações em 2004-2014. O Nordeste foi responsável, em média, por 45,4\% do total das pessoas ocupadas (45,8\% em 2004 e 45,1\% em 2014). Na sequência, aparecem Sudeste, Sul, Norte e Centro-Oeste, com 21,2\%, 16,5\%, 10,7\% e 6,3\%, respectivamente.

Tabela 1: Evolução da PEA agrícola ocupada de 10 anos ou mais de idade, no período 2004 a 2014. Brasil, Região Norte e Estados

\begin{tabular}{|c|c|c|c|c|c|c|c|c|}
\hline $\begin{array}{l}\text { Unidade da } \\
\text { Federação }\end{array}$ & 2004 & 2007 & 2009 & 2011 & 2014 & $\begin{array}{c}\text { Ta2 } \\
04 / \\
(\% \text { a }\end{array}$ & & $\begin{array}{c}\text { Variação } \\
\text { (mil } \\
\text { pessoas) }\end{array}$ \\
\hline BRASIL & 18.030 & 16.842 & 16.035 & 14.888 & 14.466 & $-2,8$ & $* * *$ & -3.564 \\
\hline REGIÃO NORTE & 1.963 & 1.620 & 1.619 & 1.855 & 1.691 & 0,0 & & -272 \\
\hline Rondônia & 272 & 225 & 240 & 220 & 205 & $-2,5$ & $* * *$ & -67 \\
\hline Acre & 98 & 81 & 84 & 99 & 87 & $-0,7$ & & -12 \\
\hline Amazonas & 298 & 279 & 293 & 364 & 326 & 1,6 & $*$ & 28 \\
\hline Roraima & 41 & 54 & 38 & 47 & 43 & $-2,9$ & & 2 \\
\hline PARÁ & 1.003 & 757 & 713 & 878 & 804 & 0,7 & & -199 \\
\hline Amapá & 23 & 23 & 25 & 29 & 28 & 2,2 & $*$ & 5 \\
\hline Tocantins & 228 & 200 & 225 & 219 & 199 & $-1,0$ & $*$ & -29 \\
\hline
\end{tabular}

Fonte: Tabulações especiais da PNAD/IBGE.

Nota: $* * * \mathrm{e}^{*}$ indicam, respectivamente, $99 \%$ e $90 \%$ de confiança.

No período considerado, houve redução de 272 mil pessoas ocupadas na agropecuária da região Norte. Desse total, 199 mil (ou 73\% do total) foram registradas no estado do Pará.

Um destaque marcante é observado no caso do Pará, que detém de 44-51\% da PEA agrícola regional. Em um patamar inferior, algo em torno da metade, situou-se o estado do Amazonas (15$20 \%$ ), o que também foi observado no caso dos estados representantes de novas fronteiras agrícolas: Rondônia (12-15\%) e Tocantins (12-14\%). Os outros Estados apresentaram valores baixos (Acre: 5\%) ou muito baixos (Roraima: 2-3\%; Amapá: 1-2\%) na PEA agrícola regional.

No caso do Tocantins, Rondônia e Pará, observou-se uma redução do PEA agrícola entre os anos de 2004 e 2014, muito embora todos estes estados estejam reconhecidos como espaços das novas fronteiras agrícolas com apoio de políticas públicas, sob argumento da geração de emprego e renda estimuladas por uma conjuntura internacional favorável à produção de commodities agrícolas.

Em Tocantins, estado que se notabiliza pela produção da soja, muito embora a pecuária também conste historicamente na sua pauta, Souza e Barros (2019) afirmam que:

A porção centro-norte do país, onde se localiza o estado do Tocantins, constitui uma área de expansão recente dessa fronteira agrícola, integrante da área designada como MATOPIBA (Maranhão, Tocantins, Piaú́ e Bahia), configurando-se gradualmente como uma região produtiva do agronegócio. (2019, p. 125).

Segundo os autores, tal expansão "tem atraído um número crescente de produtores e empresas que, em geral, já possuem experiência em outras áreas, como Goiás, Mato Grosso, oeste da Bahia e 
sul/sudoeste do Piauí" (Souza; Barros, 2019, p. 125). Apesar de reconhecer as transformações em curso, os autores questionam aspectos ambientais, conflitos entre grandes produtores rurais e comunidades locais e o imbricamento entre a política e os rumos do agronegócio e das ações ambientais no estado. De maneira geral, constata-se que as ações no MATOPIBA têm ocasionado o aumento de área cultivada de grãos sob alta mecanização, o que pode implicar a redução da demanda por força de trabalho, aspectos que têm sido considerados como sinônimo de modernização da agricultura empresarial.

De modo bastante otimista, Oliveira (2018) conclui que o agronegócio no Tocantins está em fase de consolidação, assim como sua economia. Com base nos dados do Censo Agropecuário de 2006 e de modelos estatísticos, ele estimou e analisou a função de produção agropecuária agregada dos 139 municípios do estado. O autor concluiu que “A variável mão de obra apresentou a menor elasticidade parcial de 0,33 , pode-se inferir que a agricultura e pecuária do Estado do Tocantins possui alto grau de utilização dessa variável” (Oliveira, 2018).

Em Rondônia, Oliveira e Amaral (2018) reconhecem que o surto demográfico e econômico, incentivado nas décadas de 70 e 80 com o fenômeno da colonização pública provocou crescimento da economia vez que o Estado tem o sexto maior rebanho bovino do país, sendo quinto em exportação de carne e o oitavo produtor de leite. Os autores são críticos quanto à integração regional na sua totalidade e a questão ambiental, e afirmam que:

\footnotetext{
Para o caso em estudo, o processo de colonização e modernização da agricultura no uso do território, com a expansão do agronegócio, sobretudo da lavoura de grãos, em especial da soja, impõe a expulsão de camponeses para outras áreas rurais ou para cidades. Desse modo, prevalece a lógica do capital na organização do território e nas relações sociais estabelecidas no convívio em sociedade (Oliveira; Amaral, 2018, p. 41).
}

O caso do Pará, bem como o de Tocantins e Rondônia, remete à nova formatação de colonização empreendida na região, a qual consiste basicamente na abertura de estradas, proposição de grandes projetos econômicos, empreendimentos fortemente subsidiados pelo Estado, em especial voltados à pecuária e cultivos como soja e dendê. Ressalta-se a tensa coexistência de uma agricultura de aprovisionamento por diferentes grupos que têm na produção familiar o sustentáculo, com essa 'nova agricultura' empresarial, levado a cabo, muitas vezes por grupos exógenos e que impõem um padrão de expansão de monocultivos.

Em se tratando da PEA agrícola ocupada quanto ao lugar de moradia para o mesmo período no Pará (Gráfico 1), há tendência de redução já no início da série (em 2005) e posterior oscilação em torno de 750 mil pessoas, com uma variação de 646-877 mil pessoas no período considerado. 


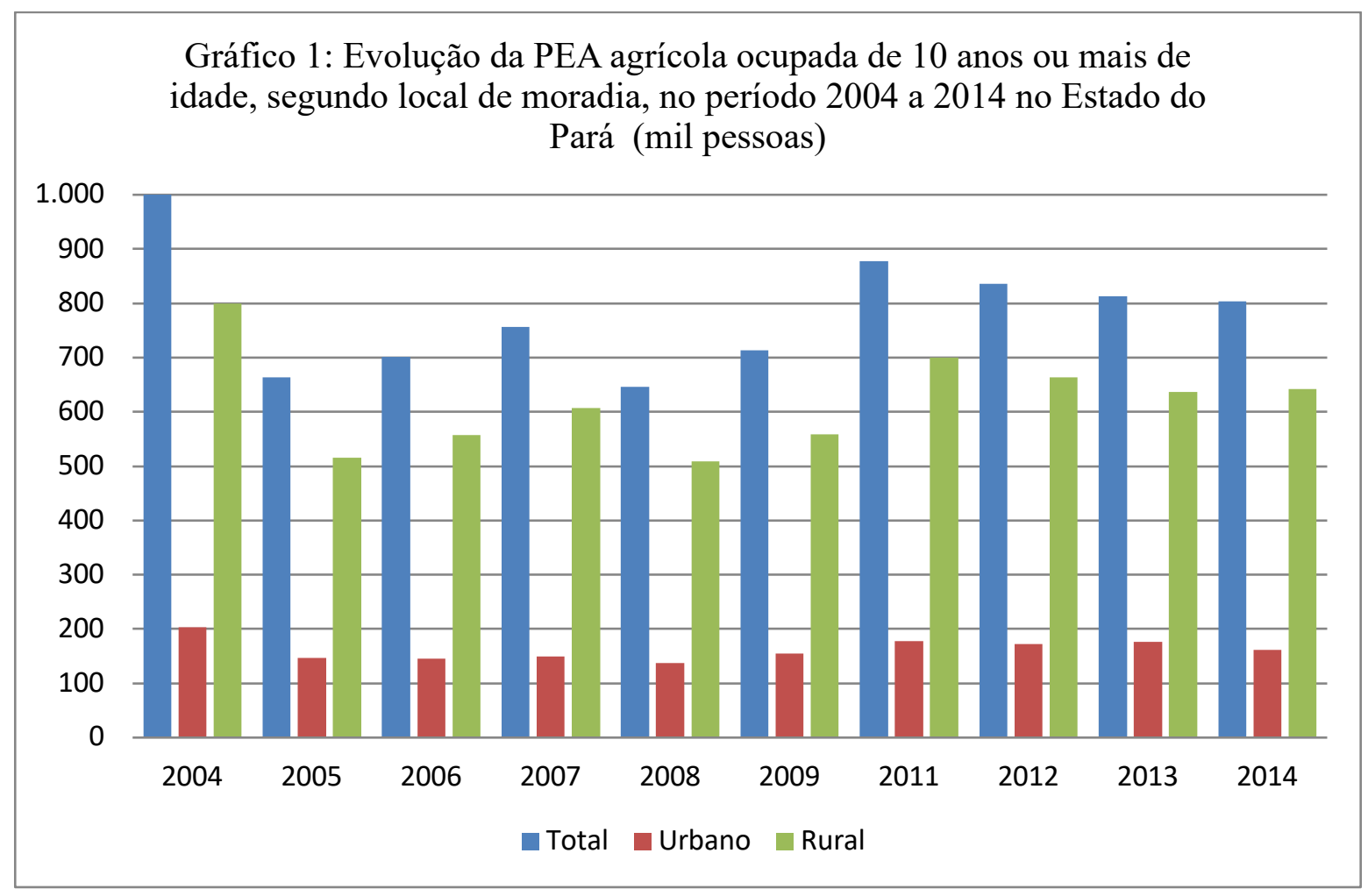

Entretanto, a relação urbano/rural manteve-se praticamente constante, na qual cerca de $80 \%$ correspondeu ao rural e o restante ao urbano. Essa fração urbana correspondente a $20 \%$ atesta um patamar constante relativo aos serviços públicos disponibilizados na escala local.

No caso do Amazonas e dos estados de Roraima e Amapá observou-se um incremento de PEA agrícola. Os três estados caracterizam-se por uma agricultura predominantemente tradicional e diversificada, com destaque para a produção de mandioca, pecuária e, de forma incipiente, a soja. $\mathrm{O}$ extrativismo animal e vegetal merece destaque.

O estado do Acre se notabiliza por iniciativas de vertente ambiental, em parte, fruto do legado de Chico Mendes. Não obstante, segundo Amaral e Lima (2018, p. 15): “O setor primário ainda está longe de ser um grande empregador". Deve-se considerar que os dados utilizados pelos autores são da RAIS e, como tal, não revelam relações não mercantis que caracterizam processos de trabalho com base em relações familiares. Os autores indicam que o setor secundário, apesar do seu crescimento, não consegue alavancar a economia local há expressivo crescimento do setor terciário em número formais de emprego, mas a alta rotatividade do setor é um grande problema para os trabalhadores. A administração ainda continua como o maior empregador no estado (Amaral e Lima, 2018).

Os dados da Tabela 1 mostram que o Estado do Acre ocupava quase 90 mil pessoas na PEA agrícola em 2014, superando apenas os Estados de Roraima e Amapá em termos de participação (absoluta e relativa). No período analisado, a redução da PEA agrícola acreana foi de $-0,7 \%$ ao ano (ou cerca de 12 mil pessoas no total). 
Evolução da PEA rural não agrícola

Com relação à PEA rural não agrícola, mais uma vez o estado do Pará apresentou elevado destaque, correspondendo inicialmente a aproximadamente $60 \%$ do total regional e alcançando cerca de 70\% (Tabela 2). Em função disso, houve uma variação positiva de 106 mil pessoas residentes em áreas rurais e ocupadas em atividades não agrícolas na região Norte.

Tabela 2: Evolução da PEA rural não agrícola de 10 anos ou mais de idade no período 2004 a 2014. Região Norte e Estados

\begin{tabular}{|c|c|c|c|c|c|c|c|c|}
\hline \multicolumn{9}{|c|}{ (milhares de pessoas) } \\
\hline $\begin{array}{l}\text { Unidade da } \\
\text { Federação }\end{array}$ & 2004 & 2007 & 2009 & 2011 & 2014 & $\begin{array}{c}\text { Taxa } 04 / 09 \\
(\% \text { a.a. })\end{array}$ & $\begin{array}{c}\text { Taxa } \\
11 / 14 \\
\text { (\% a.a.) }\end{array}$ & $\begin{array}{l}\text { Variação } \\
\text { (mil } \\
\text { pessoas) }\end{array}$ \\
\hline \multicolumn{9}{|c|}{ 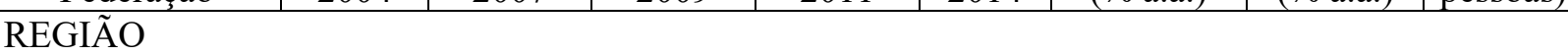 } \\
\hline NORTE & 631 & 795 & 830 & 643 & 737 & 3,9 & $4,8 *$ & 106 \\
\hline Rondônia & 66 & 68 & 66 & 51 & 54 & 0,1 & 1,7 & -12 \\
\hline Acre & 27 & 40 & 32 & 18 & 27 & 9,1 & 13,9 & 0 \\
\hline Amazonas & 87 & 75 & 128 & 63 & 74 & 4,3 & 4,2 & -13 \\
\hline Roraima & 13 & 17 & 23 & 12 & 16 & $10,8 * *$ & 10,2 & 3 \\
\hline PARÁ & 390 & 531 & 517 & 453 & 509 & 3,6 & 4,5 & 119 \\
\hline Amapá & 11 & 17 & 13 & 10 & 16 & 6,6 & 12,2 & 5 \\
\hline Tocantins & 38 & 47 & 51 & 37 & 42 & $5,5 * * *$ & $4,4 * *$ & 4 \\
\hline
\end{tabular}

Fonte: Tabulações especiais da PNAD/IBGE.

Nota: $* *$ e $*$ indicam, respectivamente, $95 \%$ e $90 \%$ de confiança.

Em um limiar inferior, destaca-se o estado do Amazonas (oscilando entre 9 e $15 \%$ do total regional), seguido por Rondônia (7-10\%) e Tocantins (6\%). Os outros estados (Acre: 3-5\%; Roraima: 2-3\% e Amapá: 2\%) tiveram uma expressão muito inferior, seja pela própria dimensão da PEA, seja pela menor oferta de atividades no mercado de trabalho não agrícola.

Regionalmente, a razão PEA agrícola e não agrícola apresentou superioridade da primeira, se situa entre $66 \%$ e $76 \%$, ao longo do período. Entretanto, algumas distinções puderam ser observadas. Os estados do Tocantins (81-86\%), Amazonas (70-85\%) e Acre (67-85\%) apresentaram valores de PEA agrícola superiores, quando comparados aos estados de Rondônia (77-81\%), Roraima (62-79\%), Amapá (58-75\%) e Pará (58-72\%). Esse comportamento do estado do Pará pode indicar uma maior diversificação de atividades exercidas no meio rural, provavelmente associado às atividades de exploração mineral, que geram cerca de 300 mil empregos (Simineral, 2018).

A importância do trabalho feminino

A literatura registra, muito embora abaixo da importância que o fato exige, o cotidiano de mulheres da Amazônia, indígenas e não-indígenas, agroextrativistas (Simonian, 2001), pescadoras (Rodrigues; Scherer, 2017), extrativistas (Fernandes; Mota, 2014) e agricultoras (Nascimento, 2017). Estes estudos têm em comum a pluralidade de atividades realizadas pelas mulheres entre as esferas da produção e da reprodução. 
Tabela 3: Evolução da PEA agrícola feminina ocupada de 10 anos ou mais de idade no período 2004 a 2014. Região Norte e Estados

\begin{tabular}{|c|c|c|c|c|c|c|c|}
\hline $\begin{array}{l}\text { Unidade da } \\
\text { Federação }\end{array}$ & 2004 & 2007 & 2009 & 2011 & 2014 & $\begin{array}{c}\text { Taxa } \\
04 / 14 \\
\text { (\% a.a.) }\end{array}$ & $\begin{array}{c}\text { Variação } \\
\text { (mil } \\
\text { pessoas) }\end{array}$ \\
\hline \multicolumn{8}{|l|}{ REGIÃO } \\
\hline NORTE & 574 & 490 & 461 & 521 & 474 & $-0,9$ & -100 \\
\hline Rondônia & 99 & 73 & 82 & 56 & 56 & $-5,3 * * *$ & -43 \\
\hline Acre & 29 & 30 & 25 & 37 & 24 & $-3,0$ & -5 \\
\hline Amazonas & 76 & 77 & 85 & 113 & 93 & 2,1 & 17 \\
\hline Roraima & 8 & 15 & 10 & 16 & 11 & $-2,8$ & 3 \\
\hline PARÁ & 293 & 234 & 185 & 234 & 229 & $-0,2$ & -64 \\
\hline Amapá & 6 & 5 & 6 & 4 & 7 & $-1,2$ & 1 \\
\hline Tocantins & 64 & 56 & 68 & 61 & 55 & $-1,2$ & -9 \\
\hline
\end{tabular}

Fonte: Tabulações especiais da PNAD/IBGE.

Nota: $* * *$ indica $99 \%$ de confiança.

Modo geral, a participação feminina representou cerca de $30 \%$ do total para o período estudado, em relação à PEA masculina. Entretanto, regionalmente, pode-se observar uma pequena redução a um patamar de $28 \%$. Esse padrão foi observado de modo mais acentuado nos estados de Rondônia e Acre (de 38\% a 27\%). Enquanto que nos estados do Amazonas, Pará, Roraima e Tocantins essa oscilação foi menos acentuada, situando-se entre 20 e 33\%. A menor participação feminina foi observada no estado do Amapá, oscilando entre 15 e 25\%, ao longo do período.

Vale reforçar que, para o total da região, houve uma redução de 100 mil pessoas ocupadas na PEA agrícola feminina, no período 2004-2014. O estado de Rondônia teve a maior taxa de redução (-5,3\% a.a.) ao longo do período, ao passo que o estado do Pará teve a maior redução absoluta (-64 mil pessoas) - em 2004, o Pará tinha 51\% da PEA feminina da região Norte, valor que mudou para 48\%, em 2014.

Possíveis explicações para tal redução são que a saída dos jovens para buscar outras opções de trabalho fora dos estabelecimentos gera uma demanda por trabalho no mesmo, além de que "a chance de oferta de trabalho feminina aumenta com a idade a taxas decrescentes" (Queiroz; Aragón, 2015, p.813).

Distribuição da PEA agrícola ocupada por grupos de idade

Em se tratando da evolução da PEA agrícola ocupada por grupos de idade, no período 2004 a 2014 (Tabela 4), ressalta-se que somente nas faixas etárias maiores foi assinalado um incremento significativo, o que corrobora a observação de envelhecimento da força de trabalho e de busca de outras alternativas por parte dos mais jovens, seja em atividades não agrícolas nas áreas rurais, seja em atividades nas zonas urbanas. 
Tabela 4: Evolução da PEA agrícola ocupada por grupos de idade, no período 2004 a 2014. Brasil e Região Norte

\begin{tabular}{l|r|r|r|r|r|rrr}
\hline $\begin{array}{c}\text { Unidade da } \\
\text { Federação }\end{array}$ & 2004 & 2007 & \multicolumn{1}{c|}{2009} & 2011 & 2014 & $\begin{array}{c}\text { Taxa } \\
\text { (\% a.a.) }\end{array}$ & $\begin{array}{c}\text { Variação } \\
\text { (mil } \\
\text { pessoas) }\end{array}$ \\
\hline BRASIL & 18.030 & 16.842 & 16.035 & 14.888 & 14.466 & $-2,8 * * *$ & -3.564 \\
10 a 14 anos & 1.037 & 902 & 642 & 565 & 441 & $-10,3 * * *$ & -596 \\
15 a 29 anos & 5.586 & 4.687 & 4.116 & 3.523 & 3.003 & $-6,5 * * *$ & -2.584 \\
30 a 59 anos & 8.815 & 8.676 & 8.610 & 8.295 & 8.243 & $-1,1 * * *$ & -573 \\
60 anos ou mais & 2.592 & 2.577 & 2.666 & 2.506 & 2.780 & $-0,3$ & 189 \\
REGIÃO NORTE & 1.963 & 1.620 & 1.619 & 1.855 & 1.691 & 0,0 & -272 \\
10 a 14 anos & 167 & 124 & 98 & 110 & 86 & $-5,7 * * *$ & -81 \\
15 a 29 anos & 699 & 522 & 473 & 543 & 420 & $-2,8 * *$ & -279 \\
30 a 59 anos & 899 & 786 & 834 & 978 & 947 & $1,8 * *$ & 47 \\
60 anos ou mais & 198 & 187 & 213 & 224 & 238 & $2,6 * * *$ & 40 \\
\hline
\end{tabular}

Fonte: Tabulações especiais da PNAD/IBGE.

Nota: $* * * \mathrm{e}^{* *}$ indicam, respectivamente, $99 \%$ e $95 \%$ confiança.

O envelhecimento da força de trabalho no Brasil rural e a sua relação com a migração de jovens tem sido ressaltada por diferentes analistas (Troian; Breitenbach, 2018). Associa-se ao fenômeno, a saída dos mais jovens do campo pela falta de opção de trabalho e de qualidade de vida (Resques; Mota, 2017), mas também apontam-se novas tendências nas quais um segmento da juventude reconstrói os seus projetos de persistência naquele espaço (Castro et al., 2009).

Regionalmente, ao longo de toda a série, cerca de $81 \%$ da PEA situou-se entre as faixas etárias de 15-59 anos, com destaque para a faixa etária 30 a 59 anos, compreendendo entre 46 e $56 \%$ da PEA. Nesta faixa etária, encontram-se as pessoas mais demandadas pelo mercado de trabalho, especialmente se as atividades exigem força física para sua execução e se a remuneração é feita, preferencialmente, por critérios de produtividade do trabalho. O Gráfico 5 ilustra bem esta mudança demográfica observada na região Norte no período em questão, na qual as faixas etárias acima de 30 anos tiveram crescimento significativo, enquanto aquelas até 29 anos de idade tiveram forte redução na participação da PEA agrícola ocupada.

No geral, os dados apontam para a possível migração dos mais jovens, tanto para estudar, quanto para trabalhar em centros urbanos. Mas também deve ser considerado a maior proteção ao trabalho de crianças e jovens nos estabelecimentos, por meio de políticas públicas de transferência de renda, de promoção da segurança alimentar e nutricional, e de proibição do trabalho infantil, que foram muito ativas no período 2004-2014. 


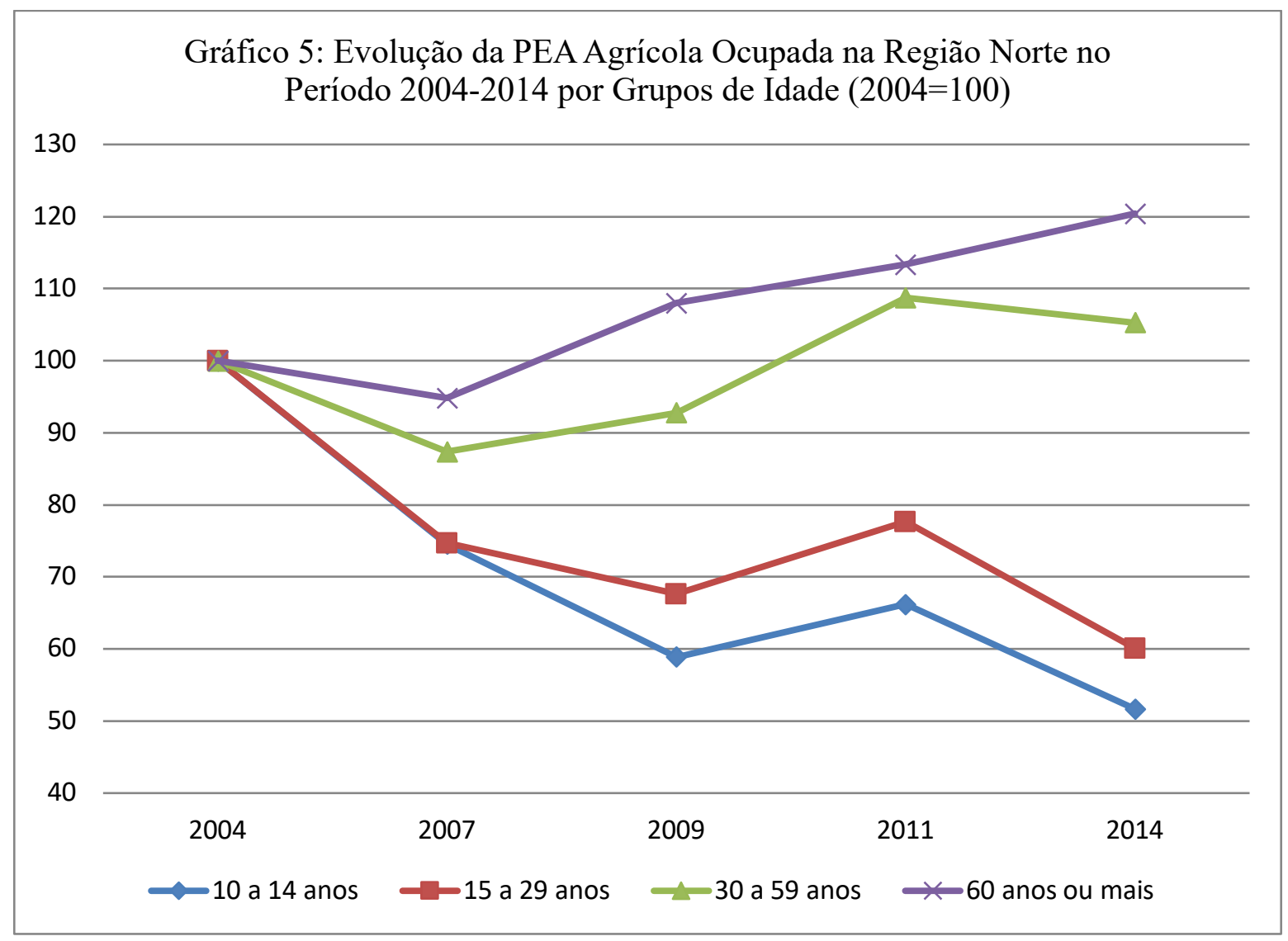

Evolução da PEA agrícola segundo a posição na ocupação

Tabela 5: Evolução da PEA agrícola ocupada de 10 anos ou mais de idade, segundo a posição na ocupação na atividade principal, no período 2004 a 2014. Região Norte

\begin{tabular}{|c|c|c|c|c|c|c|c|}
\hline Posição na Ocupação & 2004 & 2007 & 2009 & 2011 & 2014 & $\begin{array}{c}\text { Taxa } \\
04 / 14 \\
\text { (\% a.a.) }\end{array}$ & $\begin{array}{l}\text { Variação } \\
\text { (mil } \\
\text { pessoas) }\end{array}$ \\
\hline REGIÃO NORTE & 1.963 & 1.620 & 1.619 & 1.855 & 1.691 & 0,0 & -272 \\
\hline Empregador & 74 & 32 & 50 & 29 & 24 & $-9,6 * * *$ & -49 \\
\hline Conta Própria & 588 & 507 & 499 & 697 & 606 & $2,7 * *$ & 18 \\
\hline Empregados & 371 & 329 & 383 & 374 & 338 & 0,0 & -33 \\
\hline com registro formal & 58 & 56 & 67 & 84 & 91 & $4,7 * * *$ & 33 \\
\hline sem registro formal & 313 & 273 & 316 & 291 & 247 & $-1,2$ & -66 \\
\hline Não remunerados & 549 & 435 & 364 & 377 & 233 & $-5,7 * * *$ & -316 \\
\hline Autoconsumo & 381 & 316 & 324 & 377 & 489 & $2,3 *$ & 108 \\
\hline
\end{tabular}

Fonte: Tabulações especiais da PNAD/IBGE.

Nota: $* * *, * *$ e $*$ indicam, respectivamente, $99 \%, 95 \%$ e $90 \%$ de confiança.

Avaliando-se a natureza das ocupações, pode-se observar: i) redução na participação de 'empregador' (de 4\% para 1\% do PEA) e de 'membros não remunerados da família' (de 28\% para $14 \%$ do PEA); ii) estabilidade dos 'empregados' (em torno de 20\%), sendo que desses empregados pode-se assinalar o constante predomínio de 'empregados sem registro formal' (representado quase que $15 \%$ do PEA); e iii) incremento dos 'conta própria' (de 30\% para 36\% do PEA) e das pessoas dedicadas à produção para 'autoconsumo' (de 19\% a 29\%). 
Deste modo, pode-se inferir quanto à manutenção da informalidade nas relações empregatícias e o surgimento de uma nova forma centrada na iniciativa do produtor, seja sob a forma de atuação por 'conta própria' ou mesmo 'autoconsumo', o que denota ações de aprovisionamento. Entretanto, a drástica redução dos 'não remunerados' associados notadamente ao trabalho familiar indica várias possibilidades explicativas, como: a proteção ao trabalho infantil, a saída dos mais jovens, a própria compreensão do que é trabalho (diferente de ajuda). Mesmo assim, iniciativas para diminuir a penosidade do trabalho aos que permanecem no estabelecimento restam como uma demanda, tanto para as políticas públicas quanto para as instituições de ciência e tecnologia e de assistência técnica e extensão rural.

Em se tratando da evolução da PEA agrícola ocupada de 10 anos ou mais de idade, segundo a posição na ocupação, na atividade principal (Tabela 6), o Pará, em especial, manteve o mesmo padrão descrito para a região, com redução de 'empregador' e de 'não remunerados' e incremento de 'conta própria' e 'autoconsumo'. Chama atenção a mudança na estabilidade da categoria 'empregados', na qual foi possível observar uma forte redução na sub-categoria 'sem registro formal'.

Tabela 6: Evolução da PEA agrícola ocupada de 10 anos ou mais de idade, segundo a posição na ocupação na atividade principal, no período 2004 a 2014. Estado do Pará

\begin{tabular}{l|r|r|r|r|r|rrr}
\hline & & & & & & \multicolumn{1}{c}{$\begin{array}{c}\text { Taxa } \\
04 / 14 \\
(\% \text { a.a. }\end{array}$} & $\begin{array}{c}\text { Variação } \\
\text { (mil } \\
\text { pessoas) }\end{array}$ \\
\hline Posição na Ocupação & 2004 & 2007 & 2009 & 2011 & 2014 & \multicolumn{1}{c}{ (milhares de pessoas) } \\
\hline TOTAL & 1.003 & 757 & 713 & 878 & 804 & 0,7 & -199 \\
Empregador & 55 & 21 & 36 & 15 & 14 & $-11,8 * * *$ & -40 \\
Conta Própria & 271 & 234 & 205 & 330 & 274 & $5,1 *$ & 3 \\
Empregados & 219 & 175 & 208 & 197 & 187 & $-0,4$ & -33 \\
$\quad$ com registro formal & 39 & 28 & 35 & 49 & 50 & $3,2 *$ & 11 \\
sem registro formal & 180 & 147 & 172 & 149 & 137 & $-1,3$ & -44 \\
Não remunerados & 317 & 217 & 165 & 178 & 104 & $-6,0 * *$ & -213 \\
Autoconsumo & 141 & 109 & 100 & 157 & 225 & $5,0 *$ & 84 \\
\hline
\end{tabular}

Fonte: Tabulações especiais da PNAD/IBGE.

Nota: $* * *, * * \mathrm{e}^{*}$ indicam, respectivamente, $99 \%, 95 \%$ e $90 \%$ de confiança.

Como em outros estudos realizados no Brasil, todas as categorias apresentam tendência de envelhecimento, à exceção de 'autoconsumo' (Tabela 7).

Um nítido padrão de incremento no tempo médio de estudo foi assinalado em todas as categorias; com especial destaque para a categoria 'empregador'. Diferentes causas podem estar associadas, a exemplo de migração, de trabalhadores oriundos de regiões mais escolarizadas e, também, reflexo de políticas públicas para democratização do ensino, como a Educação de jovens e adultos (EJA) e do Programa Nacional de Apoio ao Transporte Escolar (Pnate). 
Tabela 7: Evolução da idade média da PEA agrícola ocupada de 10 anos ou mais de idade, segundo a posição na ocupação na atividade principal, no período 2004 a 2014. Região Norte

\begin{tabular}{l|c|c|c|c|c|c}
\hline \multicolumn{1}{c}{ Posição na Ocupação } & 2004 & 2007 & 2009 & 2011 & 2014 & $\begin{array}{c}\text { Taxa 04/14 } \\
(\% \text { a.a. })\end{array}$ \\
\hline Empregador & 47 & 52 & 49 & 52 & 52 & $0,8 * *$ \\
Conta Própria & 43 & 45 & 46 & 45 & 45 & 0,2 \\
Empregados com registro & 34 & 34 & 36 & 35 & 36 & $0,5 *$ \\
Empregados sem registro & 32 & 34 & 33 & 35 & 37 & $0,9 * * *$ \\
Não remunerados & 24 & 25 & 28 & 27 & 28 & $1,0 * *$ \\
Autoconsumo & 39 & 41 & 44 & 41 & 41 & $0,7 *$ \\
\hline
\end{tabular}

Fonte: Tabulações especiais da PNAD/IBGE.

Nota: $* * * * *$ e * indicam, respectivamente, $99 \%, 95 \%$ e $90 \%$ de confiança.

Tabela 8: Evolução do número médio de anos de estudo da PEA agrícola ocupada de 10 anos ou mais de idade, segundo a posição na ocupação na atividade principal, no período 2004 a 2014. Região Norte

\begin{tabular}{|c|c|c|c|c|c|c|}
\hline Posição na Ocupação & 2004 & 2007 & 2009 & 2011 & 2014 & $\begin{array}{c}\text { Taxa } 04 / 14 \\
(\% \text { a.a. }) \\
\end{array}$ \\
\hline $\overrightarrow{\text { Empregador }}$ & 3,8 & 5,7 & 5,3 & 6,1 & 6,6 & $3,0 *$ \\
\hline Conta Própria & 2,8 & 3,0 & 3,4 & 3,6 & 4,2 & $3,5 * * *$ \\
\hline Empregados com registro & 3,7 & 4,5 & 4,3 & 5,3 & 5,3 & $3,5 * * *$ \\
\hline Empregados sem registro & 3,3 & 3,4 & 3,6 & 3,9 & 4,2 & $3,4 * * *$ \\
\hline Não remunerados & 3,5 & 4,4 & 4,5 & 4,3 & 5,2 & $3,0 * * *$ \\
\hline Autoconsumo & 3,3 & 3,3 & 3,4 & 3,5 & 4,1 & $1,6 * * *$ \\
\hline
\end{tabular}

Fonte: Tabulações especiais da PNAD/IBGE.

Nota: $* * *$ e * indicam, respectivamente, $99 \%$ e $90 \%$ de confiança.

Principais atividades agropecuárias na ocupação da PEA agrícola

Grosso modo, o conjunto de atividades agropecuárias pode ser segmentado em função dos seguintes aspectos: i) base de mão de obra (familiar, assalariada, cooperativa); ii) relação com os mercados; iii) natureza da produção (animal, vegetal); e iv) propósito da produção (mercado, autoconsumo, ambos) (Tabela 9).

Quanto às atividades agropecuárias, há um elevado número, o que implica a diversificação de ocupações. Destacam-se a cultura da mandioca (responsável por 27\% da PEA em 2014) e da criação de bovinos (20\% da PEA em 2014). A primeira é muito associada a agricultores familiares que mantêm as roças como elemento central nos seus sistemas de produção, nas quais produzem mandioca que, transformada em farinha, constitui a base da alimentação tanto nas cidades quanto no campo na região. Mais recentemente, começam a ser desenvolvidos grandes cultivos de produtores empresariais. A segunda é desenvolvida tanto por agricultores familiares quanto por empresariais. A importância dessas atividades na economia do estado do Pará é marcante, sendo este o maior produtor de mandioca e o sexto de bovinos. 
Tabela 9: Evolução da PEA agrícola ocupada no período 2004 a 2014, segundo a atividade principal agropecuária. Região Norte

(milhares de pessoas)

\begin{tabular}{l|r|r|r|r|r|r}
\hline \multicolumn{1}{c|}{ Atividades Agropecuárias } & 2004 & 2007 & 2009 & 2011 & 2014 & \multicolumn{2}{c}{$\begin{array}{c}\text { Variação } \\
\text { (mil pessoas) }\end{array}$} \\
\hline NORTE & 1.963 & 1.620 & 1.619 & 1.855 & 1.691 & -272 \\
Cultivo de mandioca & 534 & 267 & 355 & 468 & 463 & -71 \\
Criação de bovinos & 351 & 312 & 309 & 322 & 339 & -12 \\
Criação de aves & 219 & 180 & 180 & 171 & 193 & -26 \\
Pesca e serviços relacionados & 66 & 51 & 67 & 145 & 151 & 84 \\
Cultivo de hortaliças e legumes & 70 & 63 & 102 & 82 & 91 & 21 \\
Serviços relacionados com a agricultura & 43 & 153 & 75 & 66 & 81 & 38 \\
Cultivo de outros produtos de lavoura & & & & & & \\
permanente & 142 & 86 & 64 & 82 & 64 & -77 \\
Produção mista: lavoura e pecuária & - & 34 & 88 & 168 & 63 & - \\
Cultivo de banana & 31 & 19 & 38 & 48 & 40 & 10 \\
Cultivo de arroz & 164 & 110 & 78 & 49 & 33 & -131 \\
Cultivo de milho & 54 & 42 & 58 & 68 & 32 & -22 \\
Silvicultura e exploração florestal & 58 & 31 & 23 & 29 & 31 & -27 \\
Cultivo de outros produtos de lavoura & & & & & & \\
temporária & 51 & 61 & 33 & 29 & 22 & -29 \\
Cultivo de cacau & 45 & 39 & 44 & 27 & 22 & -24 \\
Cultivo de café & 68 & 37 & 41 & 25 & 17 & -51 \\
Cultivo de soja & 5 & 3 & 3 & 6 & 15 & 10 \\
Criação de suínos & 5 & 9 & 5 & 12 & 8 & 3 \\
Criação de outros animais de grande porte & 3 & - & 1 & 11 & 7 & 5 \\
Criação de animais mal especificados & 8 & 34 & 19 & 10 & 5 & -3 \\
Cultivo de cana-de-açúcar & 13 & 19 & 22 & 6 & 3 & -10 \\
Cultivo de frutas cítricas & 8 & 4 & - & 7 & 3 & -5 \\
Demais Atividades & 26 & 68 & 13 & 25 & 9 & -17 \\
\hline Fonte Tabuco
\end{tabular}

Fonte: Tabulações especiais da PNAD/IBGE.

Outro destaque regional é a criação de aves (11\% da PEA em 2014) que, na última década, tem expandido bastante no estado do Amazonas. A atividade pesqueira (9\% da PEA em 2014) também apresentou destaque, muito embora esteja ainda subdimensionada, considerando a importância e inserção da atividade no modo de vida das populações da região.

Com importância um pouco menor, as culturas do arroz, milho e banana (2\% da PEA em 2014, cada uma) confirmam um perfil de diversificação dessas atividades, as quais têm um desempenho equivalente à silvicultura e exploração florestal (2\% da PEA em 2014). Mesmo sem registro estatístico adequado, culturas de oleaginosas, como o dendê e a soja, têm relevância assinalada, especialmente em se tratando de relações de trabalho formalizadas mais duradouras, mas que tendem a se transformar em vínculos curtos a partir da reforma trabalhista de 2017, cujas primeiras evidências se dão pela demissão de trabalhadores para readmissão por curtos períodos, como constatado nos municípios de Tomé-Açu e Acará em 2019. 


\section{RELAÇÕES DE TRABALHO NA DENDEICULTURA PARAENSE: ESTUDOS DE CASO}

Traçado um panorama geral sobre o mercado de trabalho na região Norte, passa-se agora a detalhar aspectos do cotidiano do trabalho e dos trabalhadores na dendeicultura, atividade priorizada no contexto de diversificação da matriz energética do Brasil, no Governo Lula. Trata-se de uma ação que contou fortemente com o apoio do Estado, por meio de programas de políticas públicas instituídos para a execução de um modelo de produção de uma commodity, e da ação multifaceteada dos atores segundo uma articulação que perpassa diferentes escalas na construção de novos espaços produtivos sob argumentos ambientais, econômicos e sociais (Mota; Schmitz; Mourão Júnior, 2019).

Trabalho familiar na dendeicultura

Estudos específicos sobre o trabalho familiar na produção de dendê são raros e quando privilegiam a agricultura familiar, trazem o tema do trabalho apenas secundariamente, confirmando uma tendência mundial. Em estudo de caso com agricultores familiares que produzem dendê no Pará, Ribeiro (2016) constatou mudanças no mercado de trabalho com certa carência de mão de obra, considerando que os jovens preferem o trabalho assalariado a trabalhar com as suas famílias pelos ganhos regulares e pelo desejo de autonomia. Os seus achados coincidem com os de Monteiro (2015), que destaca o assalariamento dos filhos dos agricultores com impactos na sua capacidade produtiva. Em uma comunidade quilombola, Saavedra (2017) analisou a organização do trabalho e constatou a insatisfação com o assalariamento em decorrência do peso do trabalho, do tempo gasto no deslocamento, do salário e do abandono das suas roças, com o consequente retorno ao trabalho familiar.

O perfil dos 162 agricultores familiares que produzem dendê sob contrato e que constituíram a nossa amostra constam no Gráfico 6 :

Gráfico 6: Idade e escolaridade dos agricultores com contrato.

\begin{tabular}{|c|c|c|c|c|c|c|c|}
\hline \multirow[b]{2}{*}{ Idade } & \multicolumn{6}{|c|}{ Escolaridade } & \multirow[b]{2}{*}{ Total } \\
\hline & Analfabeto & Só assina & Fundamental & Médio & Superior & Não Inf. & \\
\hline$<30$ & & 3 & 6 & 4 & & & $13(8 \%)$ \\
\hline$(30-40)$ & 2 & 26 & 4 & 2 & 1 & 1 & $36(22 \%)$ \\
\hline$(40-50)$ & 5 & 25 & 5 & & & 1 & $36(22 \%)$ \\
\hline$(50-60)$ & 6 & 32 & & 1 & & 3 & $42(26 \%)$ \\
\hline$(60-70)$ & 5 & 16 & 1 & & & 2 & $24(15 \%)$ \\
\hline$(70-80)$ & 4 & 4 & & & & 1 & $9(6 \%)$ \\
\hline Não inf. & & 1 & & & & 1 & $2(1 \%)$ \\
\hline Total & $22(14 \%)$ & $107(66 \%)$ & $16(10 \%)$ & $7(4 \%)$ & $1(1 \%)$ & $9(6 \%)$ & $162(100 \%)$ \\
\hline
\end{tabular}

Fonte: Pesquisa de campo 
Trata-se de um grupo em que mais de $60 \%$ dos seus membros têm mais de 40 anos e só assinam o nome, esta última condição é considerada uma restrição para lidar com o contrato de produção.

Para fazer frente às necessidades de força de trabalho para a produção do dendê, diferentes arranjos são instituídos. De modo geral, $87 \%$ dos entrevistados utilizam mão de obra externa, sendo observadas as seguintes modalidades: $6 \%$ dos grupos domésticos trocam dias de trabalho com outros grupos, 51\% pagam diaristas, 26\% realizam empreitas (pago por atividade e não por tempo de trabalho) e 4\% fazem mutirão. Comparando com os arranjos para as culturas anuais (principalmente a mandioca), 2\% trocam dias de trabalho, 17\% pagam diaristas, 7\% empreitam e 3\% fazem mutirão, ou seja, apenas $29 \%$ recorrem à força de trabalho externa. Para o dendê, $52 \%$ contratam diaristas, $28 \%$ empreitam e 6,8\% fazem troca de dias, sendo que as atividades envolvem adubação, capina e colheita. Quanto ao uso de mão de obra para as culturas perenes, constatou-se que $18 \%$ contratam diaristas, e $6 \%$ fazem empreita.

Em 39,6\% das famílias, seus integrantes em idade ativa para o trabalho dedicam-se exclusivamente às atividades desenvolvidas no estabelecimento, enquanto $60,4 \%$ dedicam-se parcialmente. Apesar de algumas famílias possuírem um número relativamente elevado de componentes, nem todos contribuem para o trabalho, por serem menores de idade, idosos ou por exercerem algum tipo de trabalho fora da unidade familiar.

Em duas localidades do Município de Tomé-Açu no NEP, novos arranjos que têm se instituído para o trabalho na dendeicultura. Na primeira, Santa Maria, pesquisadoras constataram que em 10 estabelecimentos houve transformação no ritmo, volume e peso do trabalho mediante o modo de cultivo do dendê com a predominância de homens em 100\% dos cultivos e prevalência do trabalho familiar (Caetano, Mota e Ferreira, 2018). As mulheres trabalham em 40\% dos casos, ainda que associadas ao trabalho considerado 'leve', situação que reflete no trabalho dos jovens que predominam no trabalho agrícola localmente, contrariando tendências confirmadas nacionalmente quanto à saída do campo por parte destes (Balsadi; Del Grossi, 2016).

$\mathrm{Na}$ quase totalidade dos estabelecimentos $(90 \%)$ há trabalhadores via contratação ocasional para a colheita do dendê, condição que implica tensões mediante a diretriz da agroindústria, que pressiona pela legalização de relações ocasionais, requisito exigido pelas certificadoras e pela legislação brasileira.

As autoras chamam a atenção sobre como a reorganização do trabalho incide nas subjetividades quanto à importância das culturas alimentares versus commodity, com a prioridade de alocação da mão de obra nesta última, por um lado. Por outro, tem influenciado na avaliação de quem é apto ou não para o trabalho na agricultura familiar, segundo diretrizes externas que extrapolam a 
tradição, e que colocam novos desafios quanto às ocupações dos filhos dos agricultores e agricultoras no futuro.

Na segunda localidade, Vila Água Azul, Mota, Ribeiro e Schmitz (2019) concluíram que há transformações nas configurações do trabalho com o aumento de arranjos que implicam na intersecção entre trabalho familiar e assalariado, vez que existem cultivos empresariais nas proximidades. Do mesmo modo que, em Santa Maria, há a priorização da produção de dendê numa diversidade de arranjos para a realização das atividades em sistemas de produção com a predominância de culturas perenes. Diferenciam-se, entretanto, porque é possível observar, de um lado, a escassez de força de trabalho nas famílias que têm assalariados na dendeicultura e, de outro, a ocorrência de mutirões e uma menor contratação de diaristas apenas nas famílias sem relação com a dendeicultura e com maior número de membros.

Por fim, a organização do trabalho tem mudanças significativas mediante a coexistência de dendê e culturas alimentares em modelos nos quais o trabalho é organizado para além dos demarcadores de sexo, geração e idade, mas também do vislumbre de outras carreiras, especialmente pelas mulheres.

Trabalhadores e trabalhadoras assalariadas na dendeicultura

$\mathrm{Na}$ dendeicultura no Pará, existem poucos estudos de caso que analisem a problemática do trabalho assalariado. A estimativa foi realizada por Brandão e Schoneveld (2015) que calcularam que a dendeicultura empregou diretamente 16.067 pessoas em 2014. Segundo os autores, duas empresas foram responsáveis por $72,4 \%$ do emprego total e calculam que é gerado um emprego para cada 9,6 a 13,9 ha, a depender das práticas de gestão. De forma bastante otimista, os autores destacam as vantagens usufruídas pelos trabalhadores assalariados em contraste com outras condições de trabalho na Amazônia brasileira, a exemplo de: base salarial ligeiramente superior ao salário mínimo oficial, bônus de produtividade, transporte, alimentação e outros benefícios que variam de empresa para empresa, como auxílio alimentação, hora intinere, seguro saúde, moradia. Segundo os autores, o salário base entre contratações formais e informais não difere. Não obstante tais dados, estudo mostra que um grande volume de processos tramita na justiça para garantir direitos trabalhistas (Morais; Menezes, 2016).

Estudos de caso, nos municípios de Tomé-Açu, Acará, Concórdia e Moju, mostram que, dos entrevistados assalariados na dendeicultura, 80\% são homens e ocupam predominantemente a função denominada pelas empresas de rural palmar, qual seja, são trabalhadores de campo que atuam principalmente na colheita dos frutos do dendê. Não registrou-se a presença de mulheres nesta função, mas em atividades relacionadas à limpeza e burocracia nos escritórios, sob argumentos do peso do trabalho e do ambiente masculino dos campos de cultivos, constatação também feita por Crispim 
Neto e Crispim (2017), em uma análise comparativa entre o mercado de trabalho rural no Brasil e no Pará entre 2004 e 2014 no qual predominam os homens. Dados dos perfis dos trabalhadores entrevistados estão demonstrados no Gráfico 7:

Gráfico 7: Idade e escolaridade Trabalhadores e Trabalhadoras Assalariadas na Dendeicultura

\begin{tabular}{|c|c|c|c|c|c|c|}
\hline \multirow[b]{2}{*}{ Idade } & \multicolumn{5}{|c|}{ Escolaridade } & \multirow[b]{2}{*}{ Total } \\
\hline & Analfabeto & Só assina & Fundamental & Médio & Superior & \\
\hline$<30$ & & & 11 & 21 & 2 & $34(48 \%)$ \\
\hline$(30-40)$ & & 1 & 11 & 9 & 1 & $22(31 \%)$ \\
\hline$(40-50)$ & 1 & 1 & 6 & 4 & & $12(17 \%)$ \\
\hline$(50-60)$ & & & 1 & & & $1(1 \%)$ \\
\hline$(60-70)$ & 1 & & & & & $1(1 \%)$ \\
\hline Não inf. & & & & 1 & & $1(1 \%)$ \\
\hline Total & $2(3 \%)$ & $2(3 \%)$ & $29(41 \%)$ & $35(49 \%)$ & $3(4 \%)$ & $72(100 \%)$ \\
\hline
\end{tabular}

Fonte: Pesquisa de campo

Independentemente da idade, reconhece-se que a força física é uma condição para o corte dos cachos de dendê que podem pesar entre 8 e $12 \mathrm{~kg}$. Entretanto, os trabalhadores relativizam a relação entre idade e assalariamento pelas experiências que têm na agricultura. Um deles comparou o trabalho na dendeicultura e na roça: “O peso é a mesma coisa. Não é tão pesado, quem é acostumado a trabalhar na roça consegue trabalhar lá. Não é pesado” (Trabalhador assalariado, 24 anos Moju).

Deve-se considerar que, dos entrevistados, $72 \%$ afirmaram ter começado a trabalhar antes dos 12 anos de idade, principalmente com a família, na agricultura de aprovisionamento. No presente, a condição civil consta em grande parte das declarações para justificar a busca de um trabalho assalariado, como revelam os depoimentos: "Porque é um jeito de conseguir um lucro melhor pra sustentar a família, da roça é muito difícil manter a família, a farinha é muito barata" (Trabalhador assalariado, 32 anos, Acará). "Por causa da podridão da mandioca, passava muita necessidade" (Trabalhador assalariado, 43 anos, Concórdia do Pará). Já para um solteiro: “Queria ter um dinheiro próprio (Trabalhador assalariado, 27 anos, Acará).

A falta de acesso à terra é também uma das razões que justificam o assalariamento: "Se o homem não tiver terra, só tem isso" (Trabalhador Assalariado, 34 anos, Moju); "Foi uma oportunidade, porque vivia de bico, qualquer uma que aparecesse pegaria" (Trabalhador assalariado, 40 anos, Concórdia do Pará).

Muito embora $75 \%$ dos trabalhadores afirmem ser de outros municípios e terem migrado para trabalhar, constata-se que os entrevistados são, predominantemente, do Pará e de municípios vizinhos, condição também constatada por Crispim Neto e Crispim (2017). Minoritariamente, 25\% é do local. Não obstante, $60 \%$ já migraram entre 3 e 8 vezes para trabalhar antes de se assalariarem na dendeicultura. Tal mobilidade não impede que a obtenção de um posto assalariado nas empresas 
decorra, em grande parte, da rede de relações que os trabalhadores têm com vizinhos, técnicos e amigos.

Os trabalhadores vivem nas proximidades dos empreendimentos ou em municípios vizinhos e, em consequência, trabalham 'perto de casa'. A constatação denota uma contra tendência aos processos que dependem do trabalho migrante 'longe de casa' nas áreas de produção para os mercados globais, a exemplo das frutas no Vale do São Francisco, no Brasil, e na Patagônia, na Argentina (Cavalcanti; Bendine, 2014); das hortaliças, na Espanha (Cánovas, 2012; Reigada, 2012) e no México (Flores; Saldaña, 2015); do dendê, na Malásia (Pye et al., 2012) e na Indonésia (Budidarsono; Susanti; Zoomers, 2013), dentre outros.

Há diferentes jornadas de trabalho e, segundo uma liderança sindical, foram negociadas para que o 'tempo família' faça parte do cotidiano dos trabalhadores. Dentre os entrevistados, constatamse três tipos: i) o sistema 4 por 4 , no qual trabalham 4 dias e folgam 4 ; ii) o sistema matutino, que vai de 6 hs às 12:30h; e iii) o sistema de dois turnos. As jornadas mais apreciadas são aquelas que permitem alternar o trabalho assalariado com o trabalho na roça. Entretanto, reconhece-se que a exaustão no sistema 4 por 4 é intensa, porque, em função do ganho por produtividade, trabalhadores chegam a estar em ação por 12 horas seguidas. Há casos, segundo informam, que necessitam tomar anti-inflamatório para suportar as dores corporais.

A expansão do assalariamento na dendeicultura incentivou a fundação de 14 sindicatos de empregados rurais agremiados na Federação de Trabalhadores Empregados Rurais do Pará FETERPA. Não obstante a pequena participação dos afiliados nas ações sindicais e a não afiliação de uma minoria, reconhece-se a importância e conquistas trabalhistas.

\footnotetext{
Assim, o sindicato corre atrás dos direitos da gente, de hora extra, de gratificação... aí eu acho que é até injusto não pagar o sindicato, porque quando eles correm atrás, eles correm pra todo mundo, aí dez não pagam vinte pagam aí (Trabalhador rural, 33 anos, Concórdia do Pará)

[...] porque hoje em dia até tem gente que reclama do sindicato e nem paga e nem é sócio eu sempre falo para eles: vocês nem pagam o sindicato e vivem cobrando se não fosse eles a gente não tinha isso nem aquilo e agora a gente tem e qualquer coisa que eles passarem do limite o sindicato está lá ao nosso favor (Trabalhador rural, 28 anos, Acará).
}

Em visita recente aos municípios de Acará e Tomé-Açu, entretanto, constatou-se que estava ocorrendo demissões. O presidente de um dos sindicatos afirmou que ainda não podia estimar o volume de demissões em decorrência dos trabalhadores não informarem e retornarem por vezes ao trabalho na condição de contratados por curtos períodos de três meses. Mas o vínculo sindical tem se dissolvido. Ele expressou a sua preocupação com o evento e o desafio enfrentado para atrair desempregados para a qualificação. Para aqueles que não obtêm contratos, o retorno ao estabelecimento da família é uma possibilidade, na qual, o salário foi utilizado para a construção de 
casas e instalação de cultivos (açaí e mandioca em pequenas parcelas). Por fím, a família e a comunidade (localidade) persistem como base da organização social e produtiva em todos os casos.

\section{CONSIDERAÇÕES FINAIS}

Com incentivo do Estado brasileiro e sob argumentos econômicos e ambientais, evidencia-se o controle de recursos naturais na produção de commodities na Amazônia brasileira, num processo reconhecidamente de expansão de fronteiras. Se, num primeiro momento, as iniciativas do agronegócio representam uma novidade quanto a enclaves de formalização de relações assalariadas mais duradouras em uma região com predomínio de relações precárias, observa-se a tendência de vínculos curtos a partir de 2019, desta feita, amparados pela legislação brasileira que foi profundamente transformada e ampara a desregulamentação.

Em se tratando da estrutura ocupacional, dentre todos os estados do Norte do Brasil, aqueles que têm mais evidência, em se tratando da expansão da produção de commodities (Tocantins, Rondônia e Pará) são os que atestam redução da PEA. Em outro conjunto de Estados (Amazonas, Roraima e Amapá) houve incremento da PEA, provavelmente porque a estrutura de produção, com forte presença de atividades agroflorestais, ajuda a explicar, pois são atividades mais intensivas em trabalho, nas quais, as famílias em diferentes comunidades tradicionais são relevantes.

O Pará detém a maior parte da PEA agrícola ocupada de 10 anos ou mais de idade, no período 2004 a 2014, expressão do movimento de expansão de fronteiras para a produção de commodities globais e também de uma agricultura familiar por meio da qual teve incremento a produção por conta própria e autoconsumo. Não obstante, o estado do Pará registrou contínua redução das ocupações na agropecuária, no período analisado (menos 199 mil pessoas ocupadas), e crescente aumento de importância das atividades não agrícolas para a população rural (cerca de 106 mil novas ocupações).

O estado do Pará centraliza mais atividades mediante maiores investimentos em infraestruturas, mas também pela atividade mineradora. Em 2014, a PEA agrícola paraense era predominantemente rural, ao passo que a PEA masculina representava cerca de $70 \%$ do total. Entre as principais atividades que demandavam mão de obra no Estado, em 2014, estavam: cultivo de mandioca; criação de bovinos; criação de aves; pesca e serviços relacionados; cultivo de hortaliças e legumes; serviços relacionados com a agricultura; e cultivo de outros produtos da lavoura permanente, dentre os quais, o dendê. Em conjunto, essas atividades responderam por cerca de $82 \%$ da PEA agrícola total.

Os estudos de caso na dendeicultura permitem conclusões específicas para os agricultores familiares e assalariados. Em se tratando dos perfis, há diferença geracional importante, como os mais jovens e mais escolarizados predominando no trabalho assalariado. 
Para os agricultores familiares, há aumento da dependência do trabalho assalariado para cumprir as tarefas no estabelecimento. Menos da metade dos membros das famílias em idade ativa dedicam-se exclusivamente ao trabalho no estabelecimento. Conclui-se que as possibilidades de outras atividades, como estudo e assalariamento fora da agricultura, estão nos seus horizontes. Assim, a organização do trabalho em estabelecimentos familiares tem sido ressignificada com uma tendência para a coexistência da especialização e da diversificação, conforme modelos em que o trabalho tem múltiplas condicionantes para além de sexo, idade e geração. No presente, as atividades agrícolas e domésticas são bem demarcadas, intensifica-se a diminuição do revezamento entre essas duas esferas, o trabalho agrícola concentra-se em homens, e as mulheres têm trabalhado mais intensamente nas atividades do roçado e no processamento de frutos, na esfera doméstica, configurando uma divisão entre as culturas destinadas ao mercado produzidas na casa e no estabelecimento. Elas também vislumbram outras carreiras.

Há simultaneidade entre o trabalho familiar e o assalariado, condição que ocorre em decorrência dos sistemas 4 por 4 e do matutino, cujos trabalhadores têm maior intensidade no assalariamento e mais tempo para se dedicarem aos cultivos familiares. Mas há também retroalimentação entre o trabalho familiar e assalariado, uma vez que membros adultos da família trabalham na condição de assalariado e os recursos do assalariamento contribuem para a manutenção da agricultura nos estabelecimentos.

Contrastando os dados secundários da estrutura ocupacional do Norte, com as evidências dos estudos de caso, diferenças e semelhanças podem ser ressaltadas. Em se tratando das diferenças, a força de trabalho alocada para a dendeicultura é mais jovem do que aquela contabilizada na PEA, sob argumento da força física que, inclusive, exclui as mulheres. Quanto às semelhanças, há a predominância de homens no assalariamento e no trabalho familiar e a redução da participação das mulheres na agricultura.

Por fim, conclui-se que as relações de trabalho formalizadas na dendeicultura tendem ao encolhimento com a reforma trabalhista de 2017, cujas consequências são diferentemente percebidas. Para um sindicalista da autodesignada 'principal representante patronal dos setores de Serviços Terceirizados e de Trabalho Temporário no Brasil': O Brasil acaba de entrar na modernidade das relações trabalhistas após a sanção, pelo presidente Michel Temer, da Lei 13.467/17, em 13 de julho" (Vander Morales, Presidente do Sindeprestem e Fenaserhtt, 2017).

Para estudiosos do trabalho no mundo rural, a Reforma Trabalhista significa que:

[...] a mudança no marco legal tem um efeito devastador: ela visa desobstruir a regulamentação para ampliar a liberdade das empresas manejarem a força de trabalho de acordo com suas necessidades, ampliando as possibilidades de flexibilização das relações de trabalho, a exemplo da terceirização, e enfraquecendo o poder dos sindicatos no processo de negociação (Galvão; Teixeira, 2018, p. 179). 
Investigar os desdobramentos da reforma trabalhista à luz dos dados secundários e de estudos de caso constituem novos desafios aos quais nos dedicaremos nos próximos estudos.

\section{REFERÊNCIAS}

ABRAPALMA. Planilha de mapeamento da palma de óleo no Brasil. Belém, PA, 2014. Não paginado.

AMARAL, J. A. da S.; LIMA, J. F. de. Crescimento do emprego formal nos municípios do Acre. Desafios - Revista Interdisciplinar da Universidade Federal do Tocantins, Palmas, v. 5, n. 3, p. 319, set. 2018.

BALSADI, O. V.; DEL GROSSI, M. Trabalho e emprego na agricultura brasileira Um olhar para o período 2004-2014. Revista de Política Agrícola, v. 25, n. 4, p. 82-96, out./dez. 2016.

BACKHOUSE, M. A desapropriação sustentável da Amazônia: o caso dos investimentos em dendê no Pará. Berlin: Freie Universität Berlin, 2013. (Fair Fuels? Working Paper).

BONANNO, A. Best practices: The artificial negativity of agri-food. In: BONANNO, Alessandro; WOLF, Steven A. (Ed.). Resistance to the Neoliberal. New York, NY: Routledge, 2018. p. 35-49.

BRANDÃO, F.; SCHONEVELD, G. The state of oil palm development in the Brazilian Amazon: Trends, value chain dynamics, and business models. Bogor, Indonesia: CIFOR, 2015. (Working Paper, 198).

BUDIDARSONO, S.; SUSANTI, A.; ZOOMERS, A. Oil palm plantations in Indonesia: the implications for migration, settlement/resettlement and local economic development. In: FANG, Z. (Ed.). Biofuels: economy, environment and sustainability. London: IntechOpen, 2013. p. 173-193.

CAETANO, M. C; MOTA, DALVA MARIA DA; FERREIRA, M. S. G. Trabalho familiar na produção de dendê sob contrato na Amazônia brasileira: o caso de Santa Maria, Pará. Santa Maria: SÉCULO XXI - REVISTA DE CIÊNCIAS SOCIAIS, p. 417, 2018. v. 8.

CASTRO, E. M. R. Processo de Trabalho e Relações de Poder na Carajás. In: D'INCAO, Maria Angela; SILVEIRA, Isolda Maciel (Org.). A Amazônia e a crise da modernização. Belém, PA: Museu Paraense Emílio Goeldi, 1994. p. 457-472.

CASTRO, E. G.; MARTINS, M.; ALMEIDA, S. L. F.; RODRIGUES, M. E. B.; CARVALHO, J. G. Os Jovens estão indo embora? - Juventude rural e a construção de um ator político. Rio de Janeiro: Mauad: EDUR, 2009. v. 1.

CASTRO, E. M. R. de. Territórios em transformação na Amazônia - saberes, rupturas e resistências. Belém, PA: NAEA, 2017.

CÁNOVAS, A. P. Trabajadores y agriculturas mediterráneas en la globalización. Regiones: Suplemento de Antropologia, México, n. 47, p. 16-20, jan./mar. 2012.

CAVALCANTI, J. S. B.; BENDINI, M. I. Globalization and change in labor relations in fruit regions of Brazil and Argentina. In: BONANNO, A.; CAVALCANTI, J. S. B. (Ed.). Labor relations in globalized food. Bingley: Emerald, 2014. p. 3-32.

CRISPIM NETO, S.; CRISPIM, C. N. S. Mercado de trabalho rural e agrícola do Pará: caracterização do mercado de trabalho atual e formação histórica do trabalhador rural. Cadernos CEPEC, v. 6, n. 10, p. 4-24, out. 2017.

CONCLA. Pesquisa CNAE Domiciliar. Disponível em: <http://www.cnaedom.ibge.gov.br/>. Acesso em: 18 dez. 2018. 
CUNHA, J. de S. Governo Temer: relações do agronegócio com o capital especulativo financeiro e impactos sobre os camponeses e a legislação agrária. Cadernos do CEAS: Revista crítica de humanidades, Salvador, n. 241, p. 301-326, set. 2017.

FERNANDES, T.; MOTA, D. M. "É sempre bom ter o nosso dinheirinho": sobre a autonomia da mulher no extrativismo da mangaba no Pará. Revista de Economia e Sociologia Rural, Piracicaba, v. 52, n. 1, p. 9-24, jan./mar. 2014.

FLORES, S. M. L.; SALDAÑA, K. S. En búsqueda del control: enganche e industria de la migración en una zona productora de uva de mesa en México. In: RIELLA, A.; MASCHERONI, P. (Org.). Asalariados rurales en América Latina. Montevideo: CLACSO, 2015. p. 73-94.

GALVÃO, A.; TEIXEIRA, M. O. Flexibilização na lei e na prática: o impacto da reforma trabalhista sobre o movimento sindical. In: KREIN, J. D.; GIMENEZ, D. M.; SANTOS, A. L. dos (Org.). Dimensões críticas da reforma trabalhista no Brasil. Campinas: Curt Nimuendajú, 2018. p. 122-155.

IBGE. Pesquisa Nacional por Amostra de Domicílios. Disponível em: $<$ https://ww2.ibge.gov.br/home/estatistica/pesquisas/pesquisa_resultados.php?id_pesquisa $=4>$. Acesso em: 21 out. 2017.

IBGE. Projeção da População: Revisão 2013. Disponível em: $<$ https://ww2.ibge.gov.br/home/estatistica/populacao/projecao_da_populacao/2013/default.shtm>. Acesso em: 18 dez. 2018.

LIMA, M. C.; OLIVEIRA, E. M. Land grabbing, fome e meio rural: Brasil e China. In: LIMA, Marcos Costa; OLIVEIRA, Eduardo Matos (Org.). Estrangeirização de terras e segurança alimentar e nutricional: Brasil e China em perspectiva. Recife: FASA, 2019.

LITTLE, P. E. Megaprojetos na Amazonía: Uma análise geopolítica e socioambiental com propostas de melhor governo para a Amazônia. [S,1.]: RAMA: ARA: DAR, 2013.

MONTEIRO, M. A. Mudar para persistir: uma experiência de resistência camponesa e a expansão do dendê na Amazônia. In: SEMINÁRIO INTERNACIONAL AMÉRICA LATINA: POLÍTICA E CONFLITOS CONTEMPORÂNEOS, 2015, Belém, PA. Anais... Belém, PA: Núcleo de Altos Estudos Amazônicos, UFPA, 2015. p. 246-270.

MOTA, D. M.; SCHMITZ, H.; MOURÃO JUNIOR, M. Oil Palm Cultivation in the Brazilian Amazon: State Actions, Interest Groups and Conflict. In: BONANNO, Alessandro; CAVALCANTI, Josefa Salete Barbosa (Org.). State capitalism under neoliberalism: the case of agriculture and food in Brazil. Lanham: Rowman \& Littlefield, 2019. v. 1, p. 93-112.

MOTA, D. M. da; RIBEIRO, L. B.; SCHMITZ, H. A organização do trabalho familiar sob a influência da produção de dendê em Tomé-Açu, Pará. Boletim do Museu Paraense Emílio Goeldi. Ciências humanas, Belém, v. 14, n. 2, p. 531-552, Aug. 2019.

MORAIS, L.; MENEZES, D. Proposta de elaboração da carta de princípios para o desenvolvimento sustentável e inclusivo da cadeia de óleo de palma do Pará: Resumo executivo sobre o mapeamento da cadeia produtiva e da realidade local e a estruturação jurídica dos empreendimentos. Belém, PA, 2016. Mimeo.

NASCIMENTO, D. A. S. do. Trabalho e autonomia em campo de domínio masculino: mulheres que têm contratos de produção com agroindústrias de dendê em São Domingos do Capim - $P A$. Belém, PA, 2017. 136 p. Dissertação (Mestrado em Agriculturas Familiares e Desenvolvimento Sustentável) - Universidade Federal do Pará, 2017.

OLIVEIRA, N. M. de. Produção agropecuária agregada: uma aplicação para o estado do Tocantins. Desafios - Revista Interdisciplinar da Universidade Federal do Tocantins, v. 5, n. 1, p. 135-147, mar. 2018. 
OLIVEIRA, V.; AMARAL, J. Amazônia e o processo de colonização da fronteira agrícola: o caso de Rondônia. Cadernos CERU, v. 29, n. 2, p. 20-43, 2018. Disponível em: $<$ http://www.revistas.usp.br/ceru/article/view/155269>. Acesso em: 13 jan. 2019.

PYE, O.; DAUD, R.; HARMONO, Y.; SUKARSA, T. Precarious lives: transnational biographies of migrant oil palm workers. Asia Pacific Viewpoint, [s.1.], v. 53, n. 3, p. 330-342, Dec. 2012.

QUEIROZ, V. dos S.; ARAGON, J. A. O. Alocação de tempo em trabalho pelas mulheres brasileiras. Estud. Econ., São Paulo, v. 45, n. 4, p. 787-819, Dec. 2015. Disponível em:

$<$ http://www.scielo.br/scielo.php?script=sci_arttext\&pid=S0101-

$41612015000400787 \& \operatorname{lng}=$ en\&nrm=iso>. Acesso em: 08 Dez. 2019.

http://dx.doi.org/10.1590/0101-416145484vqj.

RESQUES, M. F. A.; MOTA, D. M. da. Motivação de jovens para o trabalho na Amazônia paraense. Raizes, Campina Grande, v. 37, n. 2, p. 117-133, 2017.

REIGADA, A. Agricultura industrial en Andalucía y feminización del trabajo en las cadenas agrícolas globales. Regiones, [s.1.], ano 8, n. 47, p. 22-26, 2012.

RIBEIRO, L. B. O trabalho sob influência da dendeicultura em Vilas rurais paraenses. Belém, PA, 2016. 120 f. Dissertação (Mestrado em Agriculturas Familiares e Desenvolvimento Sustentável) Universidade Federal do Pará, 2016.

RODRIGUES, C. P.; SCHERER, E. F. Os significados do trabalho de mulheres pescadoras em uma comunidade da Amazônia. Review of Research, v. 6, p. 1-7, 2017.

SAAVEDRA, M. da P. C. $O$ "ir" para o assalariamento na agroindústria do dendê e o "voltar" para a comunidade quilombola: o caso de Santo Antônio em Concórdia do Pará. Belém, PA, 2017. Dissertação (Mestrado em Ciências Sociais) - Universidade Federal do Pará, 2017.

SIMONIAN, L. T. L. Mulheres seringueiras na Amazônia brasileira: uma vida de trabalho silenciado. In: ÁlVARES, M. L. M. e D‘INCAO, M. Â. (Org.). A mulher existe? Uma contribuição ao estudo da mulher e gênero na Amazônia. Belém: MPEG, 1995. p. 97-115.

SIMINERAL. Mineração no Pará, Brasil e Mundo. Disponível: $<\mathrm{http}$ ://simineral.org.br/mineracao/mineracao-para>. Acesso em: 30 abr. 2018.

SOUZA, L.; BARROS, J. Agronegócio e ambiente no Cerrado tocantinense: um panorama dos municípios com base em indicadores. Ateliê Geográfico, Goiânia, v. 13, n. 1, p. 124-149, abr. 2019.

TROIAN, A.; BREITENBACH, R. Jovens e juventudes em estudos rurais do Brasil. Interações, Campo Grande, v. 19, n. 4, p. 789-802, 2018. 